\title{
IDENTIFICACIONES, BORRAMIENTOS Y NEGACIONES: COMER Y BEBER EN ALGUNAS NOVELAS CHILENAS RECIENTES*
}

\author{
Macarena Luz Areco Morales**
}

\section{Resumen}

El objetivo de este artículo es analizar diferentes modos de representar el alimento en obras publicadas en las últimas dos décadas por tres narradores chilenos -Cynthia Rimsky, Roberto Bolaño y Alejandro Cabrera-, con el fin de estudiar los lazos existentes entre comida e identidad. De este trabajo surge un espectro que va desde la identificación hasta la negación, pasando por la neutralización del valor de lo comestible como otorgador de distinción y pertenencia.

Palabras clave: narrativa chilena reciente, comida, identidad, Roberto Bolaño, Cynthia Rimsky, Alejandro Cabrera

\section{Identification, Delection and Negation: Eating and Drinking in the Contemporary Chilean Novel}

\begin{abstract}
The aim of this article is to analyze different forms of representing food in the work of three recent Chilean novelists - Cynthia Rimsky, Roberto Bolaño and Alejandro Cabrera - in order to study the existing links between flavors, taste and identity. This analysis reveals a spectrum of meaning that considers identification, denial, distinction and belonging.
\end{abstract}

Key words: recent Chilean narrative, food, identity, Roberto Bolaño, Cynthia Rimsky, Alejandro Cabrera.

Recibido: 12-03-2013 Aceptado: 11-04-2013

\footnotetext{
* Este artículo ha sido escrito en el marco del Proyecto Fondecyt №1100543. Fue leído como ponencia en el coloquio Saberes y sabores de la literatura latinoamericana organizado por el CRLA-Archivos de la Universidad de Poitiers (17 al 19 de octubre de 2012).

** Chilena, Doctora en Literatura, Facultad de Letras, Pontificia Universidad Católica de Chile, Santiago, Chile. mareco@uc.cl. Académica Universidad Diego Portales.
} 
Cuando en el capítulo IX de La Odisea Ulises relata su breve estadía en la tierra de los comedores de loto, los lotófagos, no sólo está reflexionando o quizás ironizando sobre las veleidades de la memoria y el patriotismo, sino que, más simplemente, está aludiendo a una propiedad de la alimentación que es casi tan básica como la de permitir el sustento corporal: otorgar identidad. Según expresa el especialista boloñés en interpretación cultural de la comida Massimo Montanari: "Exactamente como el lenguaje, la cocina implica y expresa la cultura de quien la practica, es depositaria de las tradiciones y de la identidad de un grupo" (2003 12). De ahí que "en los poemas homéricos la expresión comedores de pan es sinónimo de hombres" (Montanari 2006 15), que a los franceses se los conozca como comedores de caracoles o a los gascones como "migliofagi", los que comen mijo (Montanari 2003 63).

A partir de estas reflexiones, en este artículo consideraré los alimentos como parte esencial de las representaciones identitarias del sujeto y de los pueblos; como un input fundamental de la imaginación personal y nacional, que se construyen mediante preferencias y tabúes, apropiaciones y diferenciaciones que terminan por definir un campo de lo nuestro y de lo ajeno, del yo y del otro.

Para desarrollar estas ideas, en una primera parte del trabajo explicaré brevemente las visiones teóricas que, en los segmentos siguientes, me permitirán abordar textos de tres escritores chilenos -Cynthia Rimsky, Roberto Bolaño y Alejandro Cabrera- publicados desde fines de los noventa. Advierto desde ya que es éste un abordaje desigual, pues el mayor número de páginas está destinado al análisis de tres obras de la primera autora, debido a que en ellas la ecuación alimentación-identidad es central. Si se quiere, para utilizar el campo metafórico del que tratamos, el plato principal lo constituyen los textos de Rimsky, mientras que los de Bolaño son una suerte de entremés, aunque contundente, incluso pesado, que utilizo a modo de contraste de la imaginación identitaria de Rimsky. Por último, Soldados perdidos de Cabrera me sirve para ejemplificar modos de representación que neutralizan el sistema existente en las obras anteriores.

\section{Imaginario y distinción}

La alimentación es una construcción del imaginario social, lo que significa que si bien el consumir alimentos es un imperativo físico

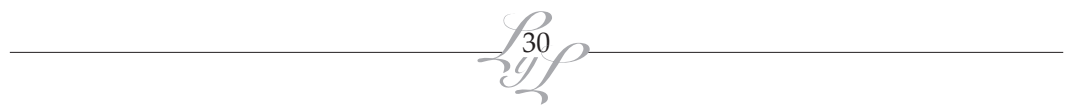


de sobrevivencia, el modo en que esta necesidad se resuelve varía significativamente en las diferentes épocas, culturas, tradiciones, religiones e incluso de persona a persona. En este sentido, el filósofo de origen griego Cornelius Castoriadis, quien desarrolló el concepto de imaginario social, explica que en ninguna sociedad el comer responde solo a la funcionalidad y a la racionalidad: "la necesidad, ya sea alimenticia, sexual, etc., no llega a ser necesidad social más que en función de una elaboración cultural" (241), dice. De acuerdo a esto, lo que distingue a la necesidad humana

es la investidura del objeto con un valor que supera, por ejemplo, la simple inscripción de la oposición 'instintiva' nutritivo-no nutritivo. . . y que establece, en el interior de lo nutritivo, la distinción entre lo comestible y lo no comestible, que crea el alimento en el sentido cultural y ordena los alimentos en una jerarquía, los clasifica en 'mejores' y 'menos buenos' (en el sentido del valor cultural, y no de los gustos subjetivos). (242)

La imaginación alimentaria instituye así los alimentos proscritos, impuros, y los preferidos, centrales, para una sociedad, que tienen un espesor cultural particular. Una muestra de ello es el hecho de que los estadounidenses consuman casiel doble de azúcar quelos franceses, según Roland Barthes, quien describe algunas de las figuraciones vinculadas al dulzor en el país del norte: "Recuerdo una canción americana muy oída; Sugar Time, el tiempo del azúcar. El azúcar es un tiempo, una categoría de mundo" (214). La comida es para este autor un signo, hondamente significativo, que constituye "un sistema de comunicación, un cuerpo de imágenes, un protocolo de usos, de situaciones y de conductas" ("Por una Psico-sociología. .." 115).

Muy pertinente para este artículo, debido a que la utilizaré más adelante en el análisis, es la noción de "distinción" planteada por Pierre Bourdieu. De acuerdo al sociólogo francés, los consumos culturales -entre los que incluye la alimentación, el vestuario, los artículos de belleza y el personal de servicio, además de los propiamente culturales, como libros, periódicos y espectáculos- le permiten "a uno afirmar su 'clase"” (16). Se oponen así los gustos de necesidad, asociados a los sectores populares, a los de lujo, propios de la burguesía, cuyos integrantes buscan por diversos medios "afirmar su distinción con respecto a la clase obrera y a sus necesidades primarias, $\mathrm{o}$, lo que viene a ser lo mismo... mantener a 
distancia a la necesidad" (182). Esto significa, simplificando al máximo, que, de acuerdo al estudio realizado por Bourdieu en Francia, mientras las clases dominantes prefieren productos magros y ligeros, más difíciles de encontrar, de mayor precio y en menores cantidades, los proletarios eligen alimentos grasos, abundantes, corrientes y baratos. A ello hay que sumarle los modos de preparación y los rituales del servicio, que, en el caso de las elites, borran la funcionalidad y materialidad de la comida a favor de la espiritualidad, y que son tanto o más importantes que la materia prima empleada. Subyace a estas preferencias una muy diferente concepción de la alimentación, según la cual "las clases populares colocan [al alimento] en el lado de la substancia y del ser, mientras que la burguesía, rechazando la distinción del dentro y del fuera, del en sí y del para otro, de lo cotidiano y de lo extracotidiano, introduce ya en él las categorías de la forma, del parecer" (199-200).

Por otra parte, la noción de lo neutro de Barthes, definido como "aquello que desbarata el paradigma", entendiendo por éste "la oposición de dos términos virtuales de los cuales actualizo uno al hablar, para producir sentido" (51), me permitirá, hacia el final del artículo, plantear cómo la novela más reciente estudiada desarticula las oposiciones binarias relacionadas con la afirmación y la negación de la identidad de que es portador el alimento y ataca la idea de distinción, a favor del gusto de necesidad de Bourdieu e incluso de una suerte de "comida de pobre" (González Turmo 309), propia de los sectores sociales más deprivados, quienes se afirman "por oposición a los demás. . . haciendo de la propia realidad, que no es sino un estado de necesidad, una elección voluntaria, un acto de libertad" (309). ${ }^{1}$

En lo que sigue, analizaré algunos casos de la narrativa chilena reciente en que la representación de la comida tiene distintos grados de relevancia, tomando en cuenta las aproximaciones teóricas que acabo

1 En los noventa surge un área de estudio dedicada en exclusiva al análisis de la comida y su relación con la cultura. Se trata de la gastrocrítica, término creado en 1990 por el crítico francés Ronald Tobin, que estudia "la pertinencia para una obra literaria de las múltiples connotaciones del comer y del beber en lo social, racial, geográfico, identitario, histórico, sexual, antropológico, religioso, filosófico, médico, cultural, psicológico, ideológico-político, genérico, lingüístico, etcétera" (De Maeseneer 24). En la introducción de su obra citada en la bibliografía, De Maeseneer efectúa una somera revisión de los distintos acercamientos al estudio de la comida en el siglo XX, desde la escuela de los Anales hasta la gastrocrítica, pasando por algunos planteamientos de Barthes y de Lévi-Strauss, entre otros. A ello hay que agregar las dimensiones metaliterarias de la tematización de la comida, pues, según afirma la crítica belga, "escribir es como Cocinar" (24). 
de esbozar, es decir, consideraré el alimento como una construcción del imaginario social, que puede entenderse como un signo de otra cosa, por ejemplo de una identidad cultural o de pertenencia a una clase social o, al contrario, de la falta de estas especificaciones e incluso de la neutralización de la oposición. Veremos así cómo las representaciones del alimento dan cuenta de diversas formas de lidiar con los imaginarios de pertenencia y de desterritorialización en contextos de viaje, diáspora y marginalidad. Entre la marca cultural y la precariedad, la identificación y la negación, las obras de los tres autores ya mencionados permiten vislumbrar un espectro de imaginaciones. En Poste restante (2001), Los perplejos (2009) y Ramal (2011) de Cynthia Rimsky los alimentos aparecen como un último resto de identidad que permite un resabio de asimilación. En el extremo opuesto, en Los detectives salvajes (1998) de Roberto Bolaño, son un dato apenas notable, una suerte de signo asignificante, no distintivo, borrado, en que la identidad es negada. Fuera del paradigma, en Soldados perdidos (2001) de Alejandro Cabrera, se asocian con la llamada "comida de pobre", vinculada con la afirmación de la precariedad y la sobrevivencia.

\section{Rimsky: la cocina como último resto de identidad}

La funcionalidad identitaria de la comida es la que aparece en la primera obra de la escritora chilena de origen judío Cynthia Rimsky (1962), Poste restante (2001), que da cuenta del viaje que una protagonista autoficticia —nombrada como "la viajera", "la extranjera", "la periodista" o "la escritora" - realiza por Israel, Egipto, Chipre y Ucrania, entre otros lugares, motivada por un álbum fotográfico encontrado en un mercado persa de Santiago, en el que aparece su apellido, aunque con i latina en lugar de la y griega. La narradora descree del valor esclarecedor de la genealogía personal: "Su historia familiar siempre fue una pregunta por el olvido más que una certeza de la cual asirse" (42), pues, señala, "(p)ara los emigrantes la historia es una línea trunca" (40). En su viaje no buscará, entonces, "parientes o el nombre en una tumba" (44), pero sí, en cambio, en cada ciudad que recorra se delectará en observar, describir, averiguar y, cuando sea posible, probar e incluso cocinar los alimentos propios del lugar. Así "un pan pita relleno con ensalada y salsa" (57), la preparación de un caldo que hace un joven en un restaurante al que "los comensales olvidan venir" (59) y las "semillas de girasol que los bebedores se echan a la boca entre trago y trago" (64) estarán entre las escenas más destacadas de su paso por Tel Aviv, mientras que, cuando en la frontera de Israel 
los policías ponen en duda su origen, la comida se le aparecerá como un medio de prueba fehaciente de identidad, al que, sin embargo, no recurrirá: "Pudo mencionar... el olor del gefeltsfish que preparaba su abuela o la cantidad de platos distintos que preparaba con un solo pollo. Pudo haberlos enumerado: Jodeletz, panitas revueltas con cebolla, consomé con mondalej, cogote relleno, chicharrones con ensalada de rábano, pollo asado, salpicón para el día siguiente" (103); pero no lo hace.

En el siguiente punto de su itinerario, Chipre del Sur, se prepara un "Plato típico": "Cueza las habas. Corte cebolla, tomate y queso blanco (cabra u oveja) en trozos grandes..." (119). La viajera, que ha escogido el lugar porque ahí vivió Lawrence Durrel (aunque después se entera de que fue en el Norte), se ha propuesto escribir ahí una novela, aunque no logra avanzar. En vez de concentrarse en su trabajo, come: "Escribo, dejo de escribir. Vuelvo de la panadería con un pan campesino redondo y tibio. Corto gruesas rebanadas y las unto con mantequilla irlandesa. Engordo" (123). Finalmente redacta la historia de un hombre que viaja a Chipre en busca de una herencia, pero lo que aparece reproducido fotográficamente en la página del frente no es ese texto sino que una lista de compras "de sobrevivencia": "2 aceite de oliva (1/2) / 2 mantequilla / 3 hogazas de pan..." (125). Tres páginas antes una lista muy parecida contiene un glosario de palabras elementales — calcetines, vaso, mano...en castellano y en griego.

Aparecen aquí las equivalencias entre palabras y alimentos señaladas por Montanari, solo que las primeras permanecen ajenas por la incomprensibilidad del idioma extranjero y finalmente traicionan - "Rimski significa baño romano, por lo que Rimski Vrelec es un lugar de baños termales" (170), le dice una amiga eslovena, terminando de esta forma con cualquier fantasía de hallar los orígenes-, mientras que la comida es una posibilidad de intercambio e integración, lo que se expresa en dos escenas de encuentro que se relatan en la novela. En la primera de ellas, datada el domingo 8 de marzo, la viajera cocina "una receta de estofado que mi madre preparaba los domingos" (132), la que comparte con otras dos inmigrantes: "En el bar de P. una rumana que fue violada, una joven de Moldavia que vino engañada a trabajar como prostituta y una viajera chilena almuerzan estofado de cerdo preparado con una receta familiar que tal vez vino de Ucrania" (132). Es notable el que la carne empleada en este caso esté prohibida para los judíos, pues en ello se percibe la falta de compromiso del personaje respecto a los 
tabúes alimentarios que impone la religión. No obstante, en la medida en que se acerca al poblado del que proviene su abuelo se irá haciendo más evidente su cercanía con las tradiciones culinarias de sus antepasados. Por ejemplo, en un mercado de Podil se encuentra con alimentos característicos de la alimentación del centro y el este de Europa que se cocinaban en su familia: "La espesura de la crema ácida, el olor a la leche cortada al sol que su abuela destilaba en una media para conseguir ricota... el largo mesón de verduras en conserva, berenjenas, repollos, zanahorias, pepinillos" (208). Al final de los puestos una joven ofrece unos pepinillos blancos y blandos. Un saber transmitido desde el pasado le permite al personaje darse cuenta de que la preparación defectuosa se debe a la falta de sal. Y es que, como indica Ariel Toaff en su estudio sobre cocina judía, lo último que permanece, más allá de la fe o el respeto de las prohibiciones, es la comida: “Costumbres y tradiciones alimentarias, inquietudes irracionales, gustos y nostalgias hacían que hasta en los casos extremos el paladar abandonara el judaísmo más lentamente y de mala gana que el corazón o la mente" (139). Una segunda escena de encuentro se produce casi al final de la narración, cuando la viajera llega a Ulanov, el pueblo en que nació el padre de su padre, donde no halla ninguna seña de sus antepasados, pero sí prepara y come, con el nieto de un emigrante polaco, cuya familia es la más antigua del pueblo, "grasa frita con papas, cebolla y huevo, como hacía su abuelo en 1906" (216). ${ }^{2}$ De este modo vemos cómo, si bien la narración construida en Poste restante hace explícitas las imposibilidades de recuperar el origen, en una suerte de argumento secreto se sostiene la pervivencia sin fin de los olores, las preparaciones y los sabores, que permiten comunión, aunque sólo sea contingente y momentánea.

La comida aparece así en esta primera obra de Cynthia Rinsky como la única marca identitaria que se mantiene más allá del exilio, el olvido, los kilómetros de distancia, la falta de documentos y de testimonios, la confusión de las letras y las incomprensiones de la palabra. Recetas, preparaciones, ingredientes, degustaciones compartidas constituyen, aunque quizás ni siquiera la viajera lo perciba, el último baluarte de la

2 Notemos que la escena es relatada en un bar "que huele a vodka y pescado salado" (216), al que la protagonista ha llegado, "lamentando que ya no sea posible Ulanov", y que la elemental preparación — que, dicho sea de paso, refiere al modelo alternativo a la cocina mediterránea (basada en el aceite de oliva, el pan y el vino), la dieta de la Europa "bárbara" que tiene como elementos centrales la carne, la grasa animal y la cerveza - se repite tres veces en no más de una página. 
identidad que mira hacia el pasado y la única posibilidad de establecer nuevos intercambios en vistas al futuro.

En el imaginario de la autora, la identidad judía se concibe como una suerte de imposible, pues, como se dice en Los perplejos, su tercera obra, en lo que podría ser una suerte de conclusión de Poste restante, "ya... no hay un pueblo" (186). Así, esta nueva novela prosigue con el tema de la identidad, incluidas las prohibiciones alimentarias, relatada como una tradición que se extingue, puesto que su historia es la del filósofo y médico judío Maimónides, que es obligado a dejar su Córdoba natal y debe deambular por comunidades africanas en las que la inevitable pérdida de la tradición se hace evidente. Para conocer la vida y obra de este personaje, la narradora, ahora llamada escritora, viaja a un congreso de filosofía medieval en Córdoba, donde un académico, máximo experto en el sabio judío, le explica la imposibilidad del conocimiento, mientras come una tostada con aceite de oliva:

- ¿Puedes imaginarte que la mayoría de los profesores que escuchaste ignoran el idioma en que Maimónides y Averroes escribieron sus obras? No solo eso. Los autores que citan en sus ponencias tampoco entienden hebreo ni árabe antiguo. - El académico propina un mordisco a la tostada. Una gota de aceite cae por su mano, antes de que se siga derramando la acerca a la boca y le pasa la lengua. Luego toma una servilleta, deja la tostada en el plato y continúa con su idea-: Es imposible que alguien pueda entender a estos filósofos si ignoran la lengua en la que escribieron.

El académico vuelve a tomar la tostada pero esta vez ninguna gota se derrama en su cuerpo.

- La verdad del pensamiento de estos filósofos se encuentra en el lenguaje.

Me muero por comer una tostada con aceite pero solo he pedido café. (99)

La conversación termina en la frustración, pues los veinte minutos concedidos por el profesor se acaban y éste no ha podido decir nada importante sobre Maimónides. Queda, no obstante, la idea de que si bien el saber es inalcanzable — sobre todo porque la barrera del lenguaje lo impide-, el sabor — representado por la tostada con aceite de oliva, alimento clave en la identidad de la cocina mediterránea- es una pulsión 
plenamente vigente. Si bien la verdad queda fuera del lenguaje, todavía parece gotear desde el pan que la narradora ansía.

En la cuarta novela de Rismky, Ramal, el problema se precisa en la identidad chilena. A través de la historia del encargado de un proyecto turístico al que se denomina "el que viene de afuera" (106), se relata cómo el antiguo ramal de trenes Talca-Constitución, que comunica pequeñísimos pueblos en el sur de Chile, ha casi desaparecido. Dentro de esta narración se mencionan comidas y bebidas típicas como el chancho en piedra, el queso de cabeza, el vino pipeño, los chicharrones de cerdo y la chanfaina. Las recetas de estas preparaciones son lo último con que el lector se queda, pues son dispuestas en las notas ubicadas al final del libro. Nuevamente pareciera que el comer y el beber, ahora en el olvidado campo chileno, constituyen el resto de identidad que permanece.

\section{Bolaño: la negación de la identidad nacional y culinaria (o la comida como patada en el estómago)}

En el polo opuesto de lo que ocurre en la narrativa de Rimsky, en las obras de Bolaño la alimentación es un significante casi ausente que no otorga identidad. Así, en ellas rara vez se come y cuando se lo hace se trata de alimentos funcionales, carentes de especificidad, tipicidad, detalles, sabor, olor. Por ejemplo, en Los detectives salvajes (1998), la torta con jamón que consume el joven poeta García Madero en una plaza donde aparece un ratón (20), de la que no se menciona más que el ingrediente que la compone, o los alimentos más bien indiferenciados que los real visceralistas consumen en los cafés, como se muestra en el siguiente reporte del mismo personaje: "Pancho y yo nos encontramos en el café chino El Loto de Quintana Roo... y tras tomar varios cafés con leche y algunas cosas más sólidas (que pagué yo), partimos rumbo a la Colonia Condesa" (37-8). Lo que sucede es que la pulsión en esta novela no es alimentaria, sino principalmente sexual — se trata de jóvenes poetas casi adolescentes preocupados fundamentalmente por lo que García Madero llama "mi educación sexual" (23) - y también drogadicta y alcohólica. Así, Lima y Belano, los jefes del realismo visceral, trafican marihuana Golden Acapulco (27), "vulgo mota" (196), y es lo que le ofrecen en uno de sus primeros encuentros a García Madero en el baño de un café donde éste ha tenido una experiencia sexual inicial con una mesera; el poeta argentino Ernesto Logiacomo piensa que lo han drogado debido a que 
ve alucinaciones en los Bosques de Chapultepec; y los mismos Lima y Belano beben varias botellas de mezcal Los suicidas en su entrevista con el anciano vanguardista Amadeo Salvatierra, quien también alucina. En todas estas escenas, como en la mayoría de las representadas en la novela, la comida está ausente.

Para intentar interpretar esta negación más allá de los gustos personales y la condición etaria de los personajes al interior de la diégesis, creo que es conveniente considerar el uso que las imaginaciones nacionalistas hacen de la alimentación. En Chile, tenemos un buen ejemplo de ello cada año cuando se celebra la independencia nacional, ocasión en que se valoran en extremo los asados, choripanes, chicha y, por supuesto, las empanadas, que es "lo que nos une como chilenos". La expresión está tomada del discurso, realizado el 14 de septiembre de 2012 por el presidente Sebastián Piñera al inaugurar la fonda oficial "La grandiosa Bertita", donde conminó a sus compatriotas a "celebrar como Dios manda", aunque aconsejándolos: "Vamos a tener cinco días para celebrar nuestras Fiestas Patrias y ojalá lo hagamos con alegría, con harta chicha, con harta cueca, con harta empanada, pero también con moderación y prudencia, porque normalmente en estos días muchos chilenos y chilenas pierden la vida y eso no queremos que ocurra" ${ }^{3}$.

Si consideramos este empleo de la comida, podemos aventurar una explicación del borramiento que hace Bolaño de ella. El escritor que partió de Chile a los 14 años, que vivió en México y en distintos lugares de Cataluña, que admiró, al mismo tiempo que denostó, a la vanguardia política y artística internacionalista, aparece como completamente lejano a estas utilizaciones y se opone a ellas omitiendo lo culinario. Mi idea es que Bolaño niega la alimentación como niega la identidad nacional. Esto último lo expresa en un muy citado párrafo de su llamado discurso de Caracas:

a mí lo mismo me da que digan que soy chileno, aunque algunos colegas chilenos prefieran verme como mexicano, o que digan que soy mexicano, aunque algunos colegas mexicanos prefieren considerarme español, o, ya de plano, desaparecido en combate, e incluso lo mismo me da que me

3 <http:/ / www.cooperativa.cl/ presidente-pinera-inauguro-las-fondas-del-parque-o-higgins / prontus_nots / 2012-09-14/213728.html>, consultado el 15 de septiembre de 2012.

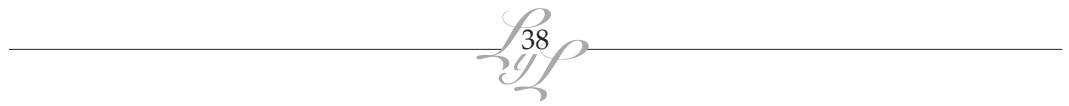


consideren español, aunque algunos colegas españoles pongan el grito en el cielo y a partir de ahora digan que soy venezolano, nacido en Caracas o Bogotá. (36)

En esta línea de negación de la identidad puede entenderse el significante vacío que es la comida en este autor. Si imaginariamente, como lo vimos en la obra de Rimsky, ésta es portadora de una identidad cultural y de una comunión, aunque sean momentáneas, y, como lo vimos en el discurso de Piñera, de una unidad nacional pensada desde el poder, el escritor iconoclasta que es Bolaño se niega a emplear los significante de este código -maíz, chancho en piedra, pipeño, empanadas- y otorga a la comida un espacio ínfimo, abstracto y generalizante, en el que evita cualquier tipo de saber, de precisión o de pulsión ligados a lo culinario.

Esta carencia de sentido hace posible en ocasiones que la comida opere como un punto de fuga que permite dar cuenta de cuestiones, desde la mira bolañana, más acuciantes, como las relaciones entre literatura y represión en el Chile de Pinochet. Así, en la crónica sobre su primera visita al país después de más de veinte años de haber partido, titulada "El pasillo sin salida aparente", Bolaño narra una comida en casa del entonces ministro Jorge Arrate y la escritora Diamela Eltit. Se repite aquí lo que ya hemos visto en cuanto a que las referencias a los alimentos son mínimas: "estamos en la mesa comiendo la cena que Jorge personalmente ha preparado. No hay carne. Alguien en la casa es vegetariano y presumiblemente ha impuesto su dieta sobre los demás. En cualquier caso es Jorge el que cocina y no lo hace nada de mal, a mí la comida vegetariana me sienta como una patada en el estómago, pero me como todo lo que me ponen" (72). La descripción, del todo carente de especificaciones, solo se sustenta en ausencias: la carne que no hay, el vegetarianismo y la supuesta imposición que alguien ha hecho de esta dieta. El anfitrión, se entiende, es un buen cocinero, aunque la expresión que Bolaño usa para indicarlo, típicamente chilena, es pródiga en negatividades: "no lo hace nada de mal" (las cursivas son mías). Bolaño, a pesar del malestar que le causa la comida que le ofrecen, come y come, pero no sabemos qué.

La crónica motivó una airada respuesta de parte de Eltit y uno se pregunta el porqué de tanto enojo. Creo que la explicación está en cierta característica "mala leche" bolañana que lo lleva, dentro del mismo artículo, a relatar, a continuación, sin motivación aparente, una conversación telefónica con Pedro Lemebel, a la que yuxtapone la 
historia de las veladas literarias que durante la dictadura se realizaban en la casa de Mariana Callejas y de Michael Townley, agentes de la DINA, que participaron, entre otros crímenes, en el asesinato de Orlando Letelier. Según relata Bolaño en esta crónica y también en Nocturno de Chile, mientras los escritores conversaban y bebían, en los subterráneos de la casa se torturaba a los opositores, que después eran enviados a lugares de detención o eran desaparecidos. Hasta lo que sé nunca nadie ha dicho que Diamela Eltit participara en estas reuniones. Por el contrario, en aquel periodo ella y su pareja de ese entonces, el poeta Raúl Zurita, integraron un colectivo de artistas - CADA - que se opuso públicamente a la dictadura. No obstante, algo de la oscuridad de la época pareciera salpicar, desde la mirada de adolescente iconoclasta de Bolaño, a quienes vivieron ese tiempo y no fueron claramente marginales como su amigo Pedro Lemebel. A partir de la cena con el ministro y la escritora y del texto que le yuxtapone, Bolaño parece querer ilustrar la conocida aseveración de Benjamin de que todo documento de cultura - y dentro de esto podemos incluir la comida - es un documento de barbarie. Para el Bolaño admirador de la vanguardia y francotirador, que se enfrenta al país-pasillo-horroroso Chile y al horror que representan los sacrificios humanos de las guerras floridas que costaron la vida a tantos jóvenes de su generación ${ }^{4}$, la cultura culinaria parece ser una expresión privilegiada de la cultura burguesa, cómplice subterránea de la barbarie latinoamericana.

\section{Cabrera: comida de pobre o la negación de la distinción}

Para terminar, me referiré, muy brevemente, a un tercer caso, la novela de 2011 de un joven escritor, Alejandro Cabrera, Soldados perdidos, donde la comida vuelve a aparecer como un elemento fundamental de la narración, pero sin las connotaciones identitarias que ésta tiene en las obras de Rimsky ni el borramiento a que se la somete en las de Bolaño. Revisemos para ello algunos fragmentos de su trama en que aparece el alimento. En el segundo capítulo, un grupo de jóvenes proveniente de un hospital psiquiátrico, entre los que se encuentra el protagonista, Rodrigo

4 En el inicio de la crónica mencionada, Bolaño se refiere a Chile como "el país pasillo" (71); como se sabe, el "horroroso Chile" proviene de un poema de Enrique Lihn; las guerras floridas son un tema del "Discurso de Caracas" y de Amuleto, entre otros. 
Rojas, que se mantienen controlados gracias a pellets y tranquilizantes, son llevados, en lo que podría ser una continuación de Hijo de ladrón de Manuel Rojas, a pintar la casa del director de la institución en un balneario de la costa central ${ }^{5}$. En un comienzo, mientras la situación se mantiene tranquila, el narrador se entretiene detallando las comidas diarias, las cuales no son platos típicos — como el chancho en piedra o los chicharrones de Ramal-, sino que alimentos corrientes y baratos, comida de pobre, se podría decir, sin la marca identitaria: "Elena prepara unas vienesas con huevos revueltos y una ensalada de tomates que todos engullen con desesperación" (41); en otra ocasión cocina "tortilla de jurel y arroz y una ensalada de betarragas" (44); y en otra "huevos con tomate y pan" (45). Muy pronto, la paz inicial se acaba cuando los personajes traban relación con un militar que se desempeña en el campo de prisioneros de Tejas Verdes, quien los lleva a ver películas a la casa de veraneo de Pinochet en Bucalemu, y avistan lo que primero parecen ser ovnis, pero terminan siendo cadáveres lanzados al mar. En este marco, los jóvenes se sacan los pellets con hojas de gillette (70) y beben, no el pipeño del sur que describe Rimsky, sino tres botellas de vodka naranja, así, mezclado ya, que han ganado en una feria playera, mientras planifican un tiranicidio que no realizan.

Varios años después, cuando Rodrigo Rojas ha cambiado su nombre por Juan Perro, y contrapuntea la escritura con el robo, continúa detallando aquello con lo que se alimenta: el día de su cumpleaños veintisiete, en unas pocas horas, come "un barros luco con mucho ají y tres schops grandes" (103); "compra una torta de milhojas para 15 personas" (104) en una pastelería del centro; pide "un vaso de vino y un sandwich" (108) en un bar cerca del antiguo Congreso Nacional; luego, en uno en Miraflores, se traga "dos aspirinas con una piscola" (109); y culmina el día en un restaurant chino, al que invita a la mesera de un "café con piernas", con el siguiente menú: "unas vainas. . . arroz chaufán, arrollado primavera, carne mongoliana, pato pekín, cerdo con piña, wantán y una botella de vino tinto" (111).

Desde hace varias décadas, Santiago y otras ciudades del país han aumentado su oferta culinaria gracias a la instalación de numerosos

5 Recordemos que la historia relatada por Rojas termina cuando su protagonista, Aniceto Hevia, junto al Filósofo y Cristián, se dirige a pintar una casa en la costa. 
restaurantes chinos, muchos de ellos en barrios populares, con su característica decoración en rojo, que mezcla neón con ideogramas, pagodas y dragones, budas y paisajes orientales, con una oferta de platos baratos, variados y contundentes. La gastronomía china se ha convertido así en una opción masiva, a la que tiene acceso un espectro social muy amplio, y que, por lo tanto, no se caracteriza por la distinción que otorga, sino por su generalidad. ${ }^{6}$ Me parece que Soldados perdidos elige esta opción popular como una forma de dar cuenta de una comida común, carente de refinamiento, hasta lo que sé no representada en la narrativa de las últimas décadas, con la excepción de La novela de otro, la segunda de Rimsky, en que también aparece uno de estos restaurantes.

A semejanza de las obras de Rimsky el alimento es en esta novela un elemento vital de la narración, que se mantiene como una pulsión viva. A diferencia de éstas, no hay casi rasgos típicos que remitan a una tradición culinaria nacional. Lo que se come es lo que come un chileno actual de clase media-baja, sin refinamientos, de lo cual son un ejemplo, como decíamos, los restaurantes chinos que son actualmente los de menor precio dentro de la oferta culinaria santiaguina. Si bien esta falta de identidad es también característica de la obra de Bolaño, lo que diferencia a ambas es que el narrador de Cabrera sí se interesa por la comida; en su relato siempre sabemos lo que los personajes consumen, aunque se trate del alimento más corriente y vulgar. Ello me permite afirmar que, en el caso de Soldados perdidos, no es ya la identidad cultural o nacional la que se pone en juego, ni para afirmarla ni para negarla, sino que lo que se ataca es la distinción en el sentido que le da Bourdieu y que explicaba al inicio de este ensayo, que vincula a la alimentación con la clase. Si consideramos a esta luz los ingredientes que se repiten en la novela — huevos, vienesas, pan, tomate, carne, queso, comida china-, además de la rapidez de su preparación y consumo, y también la importante cantidad de estos, podemos pensar que de lo que se trata precisamente es de neutralizar la oposición identidad/desautorización cultural o nacional para terminar destacando como último resto la adscripción de clase, pero no en términos de distinción, sino que de todo lo contrario, de una comida de sobrevivencia. Los alimentos que se enumeran

6 En una página de Internet, por ejemplo, se lee: “La comida china en Chile ya es una tradición, uno no sabe cuantos [sic] restaurantes chinos hay en santiago [sic], pero son muchísimos. A la hora de no cocinar es una buena alternativa económica y tiene muchas variedades en su carta". http:// walkingstgo.cl/un-chino-diferente-gao-ming/ 
y se disfrutan con apuro y fruición son los que forman la dieta diaria de un chileno de recursos temporales y económicos más bien escasos, corresponden a la "comida de pobre". Se trata, entonces, de una negativa a representarse como refinado o perteneciente a una clase superior por medio de la comida, lo que finalmente remite a una identificación, por medio del alimento, con el mundo popular y con lo proletario.

\section{Un espectro de valoraciones a modo de conclusión}

Comida identitaria, típica, en el caso de Rimsky, comida borrada en el de Bolaño y comida a granel, de pobre, en el de Cabrera. Es posible interpretar estas diferencias a la luz de distintas perspectivas. Desde el género, es evidente que las obras en donde la comida tiene el papel más destacado son las escritas por una mujer. Creo que no es necesario abundar en la asignación cultural que se hace de las labores de este tipo al sexo femenino. Sin ir más lejos, en la novela de Cabrera, quien las ejerce es Elena. Una segunda mirada tiene que ver con lo socioeconómico: mientras el mundo representado por Rimsky es el de la clase media profesional (tanto el padre de la viajera como el abuelo de "el que no es de ahí" son ambos dentistas), el de los otros dos autores se acerca al del proletariado e incluso al lumpen. Por ejemplo: la poeta vagabunda Auxilio Lacouture, la lavandera y yerbatera Cesárea Tinajero, el escritor de cartas de amor en los portales Amadeo Salvatierra, los vendedores de marihuana Lima y Belano, en el mundo bolañesco; el ladrón-escritorsicario, lanza internacional, Juan Perro en Soldados perdidos. Una tercera perspectiva, que se inserta en el contexto del proyecto de cartografía de la novela chilena reciente que desarrollé entre marzo de 2010 y marzo de $2013^{7}$, es el posicionamiento cercano al experimentalismo que se percibe en la obra de Cynthia Rimsky, en tanto es ésta una narrativa fragmentaria, preocupada por la problemática de la imposibilidad de representación del lenguaje y por la pérdida de la identidad de los sujetos diaspóricos. La recuperación de la identidad culinaria se adecua bien a este proyecto, si pensamos, por ejemplo, que ésta ha sido una temática preferente de la novela altomodernista europea. Recuérdese el complejo entramado de códigos que describe Proust en las comidas de su infancia, partiendo

7 En éste se propone un ordenamiento de la narrativa de los últimos años en cuatro territorios: realismos, experimentalismos, hibridismos y modalidades subgenéricas, como el policial, la ciencia ficción y la novela rosa. 
por la famosa magdalena, y también en el mundo de los salones en En busca del tiempo perdido, o la preparación y el consumo del riñón casi al inicio a el Ulises de Joyce. En un lugar distinto, se ubican las obras de Bolaño y Cabrera, representantes de una novela híbrida posmoderna que mezcla códigos e identidades diversas; en este caso, con particular fuerza, una tradición de la narrativa chilena que valora lo delictual e incluso lo lumpen, presente en obras como las de Manuel Rojas o Alfredo Gómez Morel. La negación de la alimentación, la oposición a la distinción culinaria y la opción por una comida popular creo que pueden leerse en este sentido.

Género, clase, distinción, experimentalismo, hibridismo, novela altomodernista, novela lumpen son conceptualizaciones que nos permiten explicar la diversidad de valoraciones que alcanza la comida en las obras analizadas, la cual, por medio de recuperaciones, borramientos, neutralizaciones y oposiciones, se mantiene como un motivo de representación y reflexión significativo en la narrativa chilena actual que porta fragmentos del imaginario social relativos al sujeto, la literatura, la clase y la nación.

\section{Obras citadas}

Barthes, Roland. "Por una psico-sociología de la alimentación contemporánea". Empiria. Revista de metodología de lasciencias sociales 11(2006):213-221.<http: / / dialnet. unirioja.es / servlet / articulo?codigo=2503390> Lo neutro. Notas de cursos y seminarios en el Collège de France, 1977-1978. Buenos Aires: Siglo Veintiuno, 2004.

Bolaño, Roberto. Los detectives salvajes. Barcelona: Anagrama, 1998.

" "Discurso de Caracas". Entre paréntesis. Barcelona: Anagrama, 2004. 31-39.

"El pasillo sin salida aparente". Entre paréntesis. Barcelona: Anagrama, 2004. 71-78.

Bourdieu, Pierre. La distinción: criterios y bases sociales del gusto. Madrid: Taurus, 1988.

Cabrera, Alejandro. Soldados perdidos. Santiago: Das Kapital, 2011.

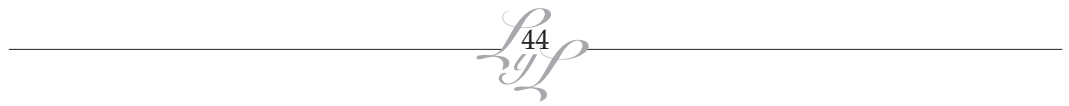


De Maeseneer, Rita. "Devorando a lo cubano. Una aproximación gastrocrítica a textos relacionados con el siglo XIX y el Período Especial". Madrid y Frankfurt am Main: Iberoamericana-Vervuert, 2012.

González Turmo, Isabel. “Comida de pobre, pobre comida”. En Mabel Gracia Arnaiz (Coord.). Somos lo que comemos. Estudios de alimentación y cultura en España. Barcelona: Ariel, 2002. 299-315.

Montanari, Massimo. El mundo en la cocina: historia, identidad, intercambios. Buenos Aires: Paidós, 2003. . La comida como cultura. Asturias: Trea, 2006.

Toaff, Ariel. “Cocina judía, cocinas judías”. En Massimo Montanari, El mundo en la cocina: historia, identidad, intercambios. Buenos Aires: Paidós, 2003. 133-146.

Rimsky, Cynthia. Poste restante. Santiago: Sangría, 2010. . La novela de otro. Santiago: Edebé, 2004. . Los perplejos. Santiago: Sangría, 2009. . Ramal. Santiago: Fondo de Cultura Económica, 2011. 